\title{
The Relationship Between Nomophobia Levels and Academic Successes in Medical Faculty Students
}

\section{Tıp Fakültesi Öğrencilerinde Nomofobi Düzeyleri ve Akademik Başarıları Arasındaki İlişki}

Nurcan Akbaş Güneş ${ }^{* 1}$, Sebahat Gücük ${ }^{l}$

\begin{abstract}
Objective: Nomophobia is a name given to the individual's fear of not being able to communicatevia mobile phone or the internet. In this study, it was aimed to to determine the level of nomophobia in medicalstudents in Turkey and manifest their effects on academic achievement. Methods: In this descriptive and cross-sectional study, a total of 332 medical students between the ages of 19-24 were included. Nomophobia Scale (NMPQ) was applied to the students. There lationship between nomophobia scales cores and academic achievements was evaluated. Results: 198 (59.6\%) of the participants were female students, $134(40.4 \%)$ were male students. When the NMP-Q scores of the participants were evaluated, 36.1\% (120) were mild, $52.4 \%$ (174) were moderate and $11.4 \%$ (38) were excessive. As the NMP-Q score s increased, it was determined that their academic success decreased more. It was observed that academic success decreased more in those who feared not having Access to information and losing connection. Conclusion: Medical education involves both a long and difficult educational process. Technological devices can make our work easier in increasing the quality of education. However, students should be told that there should be limited use. If this situation is not taken in a timely manner, it may appear as a public health problem in the future.
\end{abstract}

Keywords: nomophobia, smart phone, academic performance

\section{ÖZET}

Amaç: Nomofobi, bireyin cep telefonu ya da internet üzerinden iletişim kuramama korkusuna verilen bir isimdir. Bu çalışmada Türkiye'de tıp fakültesi öğrencilerinde nomofobi düzeylerinin belirlenmesi ve bunun akademik başarıları üzerine olan etkilerinin ortaya konulması amaçlanmıştır. Yöntem: Tanımlayıcı ve kesitsel tipte yapılan bu çalışmamıza 19-24 yaş aralığında toplam 332 tıp fakültesi öğrencisi dahil edildi. Öğrencilere Nomofobi Ölçeği (NMP-Q) uygulandı. Nomofobi Ölçeği skorları ile akademik başarıları arasındaki ilişki değerlendirildi. Bulgular: Çalışmamıza katılan katılımcıların 198'i (\%59.6) kız, 134’ü (\%40.4) erkek öğrenciydi. Katılımcıların NMP-Q skorları değerlendirildiğinde \%36.1 (120)'i hafif düzeyde, \%52.4 (174)'ü orta düzeyde, \%11.4 (38)'ü aşırı düzeyde olarak tespit edilmiștir. NMP-Q skorları ile öğrencilerin akademik başarılarının etkilenip etkilenmediği değerlendirildiğinde istatistiksel açıdan anlamlı ilişki bulunmuştur ( $\mathrm{p}=0.018$ ).NMP-Q skorları arttıkça akademik başarılarının daha fazla düştüğü tespit edilmiştir. Bilgiye erişememe ve bağlantıyı kaybetme korkusu olanlarda akademik başarılarının daha çok düştüğ̈ görülmüştür. Sonuç: Tip eğitimi hem uzun hem de zor bir eğitim süreci içermektedir. Eğitim kalitesinin artırılmasında teknolojik cihazlar işimizi kolaylaştırabilir. Fakat öğrencilere sınırlı kullanımın olması gerektiği anlatılmalıdır. Bu durum zamanında önlem alınmazsa, ilerleyen zamanda bir halk sağlı̆̆ sorunu olarak karşımıza çıkabilir.

Anahtar kelimeler: nomofobi, ak1llı telefon, akademik performans

Received date / Geliş tarihi: 19.02.2020, Accepted date / Kabul tarihi: 26.05.2020

${ }^{1}$ Bolu Abant İzzet Baysal Üniversitesi Tıp Fakültesi Aile Hekimliği Anabilim Dalı, Bolu-TÜRKIYYE.

*Address for Correspondence / Yazışma Adresi: Nurcan Akbaş Güneş, Bolu Abant İzzet Baysal Üniversitesi Tıp Fakültesi Aile Hekimliği Anabilim Dalı, Bolu-TÜRKIYE.

E-mail:drnurak@hotmail.com

Güneş Akbaş N, Gücük S.Tıp Fakültesi Öğrencilerinde Nomofobi Düzeyleri ve Akademik Başarıları Arasındaki İlişki.TJFMPC,2020;14(3): 396-402.

DOI: $10.21763 /$ tjfmpc.691384 


\section{GíRiş}

Akıllı telefonlar güncel ve kullanım kolaylığı sağlayan tasarımları, taşınabilir ve her zaman kolay ulaşılabilir olması ile birlikte hayatımızda vazgeçilmez hale gelmiştir. 2018 y1lı üçüncü çeyrekte 80,6 milyon olan cep telefonu abone sayısı \%2,8 artışla 2019 yılı üçün cü çeyrekte 82,9 milyona çıkmıştır. Mevcut grafiğe baktığımızda her geçen yıl artmaya devam etmektedir. $^{1}$ Diğer ülkelerde de durum farklı değildir. Amerika'da yapılan bir çalışmada \%95 oranında cep telefonuna sahip olma oranları gözlenmektedir. ${ }^{2}$ Ülkemizde ise bu oran \%95.9 olarak tespit edilmiştir. ${ }^{3} \mathrm{Bu}$ durum, araştırmacıların daha önceleri sigara, alkol ya da madde bağımlılığından bahsederken artık internet, oyun ve akıllı telefon bağımlılığı gibi davranışsal bağımlılıktan söz etmesine sebep olmuştur. ${ }^{4}$

Nomofobi, bireyin cep telefonu ya da internet üzerinden iletişim kuramama korkusuna verilen bir isimdir. İlk olarak İngiltere'de “ No Mobile Phobia " kelimelerinin kısaltmasından türetilmiştir. ${ }^{5}$ Son yıllarda araştırmalar akıllı telefonların aşırı kullanımının getirdiği fiziksel sorunlar ve psikopatolojiler üzerine yoğunlaşmıştır.6,7 Cep telefonunun yanında olmamasının kişiyi strese soktuğu ve konsantrasyonun bozulduğu yapılan çalışmalarda gösterilmiştir. ${ }^{7}$ Bragazzi ve arkadaşları tarafından ilk kez DSM-V kriterleri arasına alınması konusunda yeni bir öneri getirilmiştir. Bu çalışma, akademisyenlerin bu konudaki farkındalığını artırmada çok etkili olmuştur. Ayrıca yapılan bu çalışma ile bireylere psikoterapi uygulanabileceği ve ilerleyen aşamalarda farmakoterapi düşünülebileceği belirtilmiştir. ${ }^{8}$

Yapılan çalışmalar genellikle gelişime ve değişime açık, savunmasız bir nüfus olarak değerlendirilen gençlerin üzerinde durmuştur. Özellikle de ebeveyn kontrolü dişında olan üniversite öğrencileri üzerinde yoğunlaşılmıştır. ${ }^{9-11}$ Birçok ülkede tıp ve diğer fakültelerde okuyan öğrencilerin nomofobi düzeyleri karşılaştırılmış, bunun kişilik özellikleri, akademik başarıları ile ilişkisi değerlendirilmiştir. ${ }^{6,8} \mathrm{Biz}$ yaptığımız bu çalışmada Türkiye'de tıp fakültesi öğrencilerinde nomofobi düzeylerini tespit etmeyi ve bunun akademik başarıları üzerine olan etkilerini ortaya çıkarmayı amaçladık. Bu çalışma Türkiye'de tıp fakültesi öğrencilerinin nomofobi düzeylerinin ve aynı zamanda akademik başarılarının değerlendirildiği ilk çalışmadır.

\section{YÖNTEM}

\section{Çalışma Dizaynı}

Çalışma için öncelikle yerel etik kurulundan gerekli izinler alındı (2019/404). Katılımcılara bilgilendirilmiş olur formu imzalatıldı. Tanımlayıcı ve kesitsel tipte yapılan bu çalışmamız Bolu Abant İzzet Baysal Üniversitesi Tıp Fakültesi’nde öğrenim gören 198 kız ve 134 erkek öğrenci ile yapıldı. Çalışmamıza katılan öğrencilerin akademik başarılarını değerlendirirken objektif bir şekilde sınavlardan aldıkları puanların ortalaması kullanıldı. 60 puan altı alanlar akademik başarısı etkilenmiş grup, 60 puan ve üzeri alanlar akademik başarısı etkilenmemiş grup olarak değerlendirildi. Çalışmamızda ek hastalığı olan ve son 1 yılda antidepresan ya da farklı bir psikiyatrik ilaç kullanan öğrenciler çalışma dışı bırakıldı.

\section{Veri Toplama Yöntemi}

Katılımcıların değerlendirilmesi amacıyla yaş, cinsiyet, günlük ortalama cep telefonu kullanım süresi, gece cep telefonunun açık ya da kapalı olması, sabah kalktığında telefonunu kontrol etme zamanı ve akademik başarısını etkilediğini düşünüp düşünmediğini değerlendiren sorulardan oluşan bir anket formu kullanıldı. Beraberinde katılımcılara Nomofobi Ölçeği (NMP-Q) uygulandı. Ayrıca öğrencilerin sınavlardan aldıkları puanların ortalaması hesaplandi.

NMP-Q ölçeği, Yıldırım ve Correira tarafından geliştirilen ve 7'li likert şeklinde ölçülen, 20 maddeden oluşan bir ölçektir. ${ }^{12}$ Ölçekten alınabilecek minimum puan 20, maksimum puan 140'tır. 0-20 puan aralığı nomofobinin olmadığını, 21-60 puan aralığ1 hafif düzeyde, 61-100 puan aralığı orta düzeyde, 101-140 puan aralığ1 aşırı düzeyde nomofobi olduğunu göstermektedir. Ölçeğin bilgiye erişememe (4 madde), bağlantıyı kaybetme (5 madde), iletişime geçememe (6 madde), rahat hissedememe (5 madde) den oluşan dört alt boyutu bulunmaktadır. Ölçeğin Cronbach's alpha (güvenirlik katsayısı) değeri 0.95 olarak bulunmuştur. Orijinal ölçeğin dört alt boyutunun cronbach alfa değerleri sirasıyla $0.94,0.87,0.83$, 0.81 'dir. ${ }^{12}$ Türkçeye uyarlanan bu ölçeğin cronbach alfa değeri ise 0,92 'dir. Türkçeye uyarlanmış halinin alt boyutların güvenirlik katsayıları ise sirasıyla $0.90,0.74,0.94$ ve 0.91 olarak değerlendirilmiştir. ${ }^{13}$

\section{İstatistiksel Analiz}

Verilerin istatistiksel analizi için IBM SPSS v.21 versiyonu kullanılmıştır. Sayısal veriler için ortalama \pm standart sapma ve ortanca (min-max) hesaplanarak, nitelik olarak belirtilen veriler yüzde (\%) olarak ifade edilmiştir. Grup karşılaştırılmasında Mann-Whitney U testi ve Ki- 
kare testi kullanılmıştır. $\mathrm{p}<0.05$ istatistiksel olarak anlamlı kabul edilmiştir.

\section{BULGULAR}

Çalışmamıza katılan katılımcıların 198 (\%59.6)'i k1z, 134 (\%40.4)'ü erkek öğrenciydi. Katılımcıların yaş ortalaması $20.15 \pm 1.08$ olarak tespit edildi. Çalışmamızda yer alan öğrencilerin \% 71'i 19-20 yaş aralığında, \%29'u 21-24 yaş aralığında idi.

Katılımciların NMP-Q düzeyleri değerlendirildiğinde \%36.1 (n:120)'i hafif düzeyde, \%52.4 (n:174)'ü orta düzeyde, \%11.4 (n:38)'ü aşırı düzeyde olarak tespit edilmiştir. NMP-Q skorları aşırı düzeyde olan grupta, cinsiyet ve yaş açısından anlaml farkl1liklar tespit edilemedi (p=0.072).Katılımc1ların \% 89.8 (n:298)'i gece cep telefonunu açık bıraktığını belirtirken, $\% 10.2(n: 34)$ 'si cep telefonunu kapalı tuttuğunu belirtmiştir. Sabah kalktığınızda telefonunuzu ne zaman kontrol edersiniz sorumuza verilen cevaplara baktığımızda \% 77.7 (n:258)'si hemen, \%8,4 (n:28)'ü ilk 30 dakika içerisinde, \%13.9 (n:46)'u ise
30 dakika sonrasında cep telefonunu kontrol ettiğini belirtti. Öğrencilere "Bunun akademik başarınızı etkilediğini düşünüyor musunuz?" diye sorduğumuzda ise \% 57.8 (n:192)'si evet derken, $\% 42.2$ (n:140)'si hayır olarak belirtti.

Günlük ortalama cep telefonu kullanım süreleri değerlendirildiğinde \%73 (n:242)'ünün 3 saat ve üzeri, \%27 (n:90)' $\operatorname{sinin} 3$ saatin altında olduğu tespit edilmiştir. Kız ve erkek öğrencilerin günlük cep telefonu kullanım süreleri arasında istatistiksel olarak anlamlı ilişki saptanmıştır(p=0.038). Kızlar erkeklere göre günlük cep telefonunu daha uzun süre kullanmaktadır. K1z ve erkek öğrenciler arasında sabah kalktığında cep telefonlarını ilk kontrol etme zamanı açısından farklılık saptanmamıştır $(\mathbf{p}=\mathbf{0 . 1 6 2})$. Akademik başarısını etkilediğini düşünen öğrencilerin günlük ortalama cep telefonu kullanım sürelerinde ise istatistiksel açıdan anlamlı ilişki tespit edilmiştir $(p=0.013)$ (Tablo 1).

\begin{tabular}{|c|c|c|c|c|}
\hline & & Ort. telefon $\mathrm{k}$ & Im süreleri & \multirow[b]{2}{*}{$\mathrm{p}$} \\
\hline & & $<3$ saat $(\mathrm{N})$ & $\geq 3$ saat $(\mathrm{N})$ & \\
\hline Sayı (\%) & & $90(\% 27.1)$ & $242(\% 72.9)$ & \\
\hline Cinsiyet & $\begin{array}{l}\text { Kız } \\
\text { Erkek }\end{array}$ & $\begin{array}{l}42(\% 21.2) \\
48(\% 35.8)\end{array}$ & $\begin{array}{l}156(\% 78.8) \\
86(\% 64.2)\end{array}$ & $0.038^{*}$ \\
\hline $\begin{array}{l}\text { Gece telefonun açıklık } \\
\text { durumu }\end{array}$ & $\begin{array}{l}\text { Kapalı } \\
\text { Açık }\end{array}$ & $\begin{array}{l}12(\% 35.3) \\
78(\% 26.2)\end{array}$ & $\begin{array}{l}22(\% 64.7) \\
220(\% 73.9)\end{array}$ & 0.403 \\
\hline Sabah kontrolü & $\begin{array}{l}\text { Hemen } \\
\text { İlk } 30 \text { dk } \\
\text { Daha sonra }\end{array}$ & $\begin{array}{l}62(\% 24.0) \\
12(\% 42.9) \\
16(\% 34.8)\end{array}$ & $\begin{array}{l}196(\% 76.0) \\
16(\% 57.1) \\
30(\% 65.2)\end{array}$ & 0.236 \\
\hline $\begin{array}{l}\text { Akademik başarıya etki } \\
\text { durumu** }\end{array}$ & $\begin{array}{l}\text { Hayır } \\
\text { Evet }\end{array}$ & $\begin{array}{l}52(\% 37.1) \\
38(\% 19.8)\end{array}$ & $\begin{array}{l}88(\% 62.9) \\
154(\% 80.2)\end{array}$ & $0.013 *$ \\
\hline
\end{tabular}

* Ki-kare testi

**Katılımcıların kendi görüşlerine göre etkilenme durumunu belirtmektedir

Akademik başarısını etkilediğini düşünen katılımcılarda cep telefonu kullanım süresi daha uzun bulunmuştur. NMP-Q skorları ile katılımcıların yaşları değerlendirildiğinde anlamlı ilişki saptanmamıştır(p=0.089). Katılımcıların NMP-Q skorları ile cinsiyetler arasında anlamlı ilişki olduğutespit edilmiştir $(\mathbf{p}=\mathbf{0 . 0 1 1})$. Kızların NMP-Q skorları daha yüksek olarak değerlendirilmiştir.

Günlük ortalama cep telefonu kullanım süreleri ile NMP-Q skorları değerlendirildiğinde istatistiksel açıdan anlamlı ilişki tespit edilmiştir $(\mathbf{p}=\mathbf{0 . 0 0 9})$. Cep telefonu kullanım süresi arttıkça NMP-Q skorlarının arttığı gözlenmektedir. Sabah cep telefonunu kontrol etme zamanı ile NMP-Q skorları arasındaki ilişki değerlendirildiğinde anlamlı ilişki tespit edilmiştir $(\mathbf{p}=\mathbf{0 . 0 1 4})$. Sabah kalktığında cep telefonunu hemen kontrol edenlerde NMP-Q skorlarının daha yüksek olduğu görülmektedir (Tablo 2). 


\begin{tabular}{|c|c|c|c|}
\hline & & NMP-Q Skorları (ort \pm ss) & $\mathrm{p}$ \\
\hline Cinsiyet & $\begin{array}{l}\text { Kız } \\
\text { Erkek }\end{array}$ & $\begin{array}{l}71.53 \pm 23.29 \\
62.46 \pm 20.98\end{array}$ & $0.011^{*}$ \\
\hline $\begin{array}{l}\text { Gece telefonun açıklık } \\
\text { durumu }\end{array}$ & $\begin{array}{l}\text { Kapalı } \\
\text { Açık }\end{array}$ & $\begin{array}{l}77.71 \pm 27.32 \\
66.74 \pm 22.01\end{array}$ & 0.060 \\
\hline Sabah kontrolü & $\begin{array}{l}\text { Hemen } \\
\text { İlk } 30 \text { dk } \\
\text { Daha sonra }\end{array}$ & $\begin{array}{l}70.59 \pm 22.76^{\mathrm{a}} \\
56.21 \pm 20.25^{\mathrm{b}} \\
59.70 \pm 20.77^{\mathrm{b}}\end{array}$ & $0.014^{*}$ \\
\hline $\begin{array}{l}\text { Günlük ortalama } \\
\text { kullanım süresi }\end{array}$ & $\begin{array}{l}<3 \text { saat } \\
\geq 3 \text { saat }\end{array}$ & $\begin{array}{l}60.38 \pm 20.64 \\
70.65 \pm 22.96\end{array}$ & $0.009^{*}$ \\
\hline $\begin{array}{l}\text { Akademik başarıya } \\
\text { etki durumu** }\end{array}$ & $\begin{array}{l}\text { Hayır } \\
\text { Evet }\end{array}$ & $\begin{array}{l}62.40 \pm 21.42 \\
71.85 \pm 22.99\end{array}$ & $0.008^{*}$ \\
\hline
\end{tabular}

* Mann-Whitney U testi

**Katılımcıların kendi görüşlerine göre etkilenme durumunu belirtmektedir

NMP-Q skorları ile öğrencilerin akademik başarılarının etkilenip etkilenmediği değerlendirildiğinde istatistiksel açıdan anlamlı ilişki bulunmuştur ( $\mathbf{p = 0 . 0 1 8 )}$ (Tablo 3). NMP-Q skorları arttıkça akademik başarılarının daha fazla düştüğü tespit edilmiştir. NMP-Q ölçeğinin alt parametreleri değerlendirildiğinde ise bilgiye erişememe ve bağlantıyı kaybetme ile akademik başarıları arasında anlamlı ilişki olduğu gösterilmiştir( $\mathbf{p}=\mathbf{0 . 0 1 0}, \quad \mathbf{p}=\mathbf{0 . 0 1 9}) \quad$ (Tablo 3). Bilgiye erişememe ve bağlantıyı kaybetme korkusu olanlarda akademik başarılarının daha çok düştüğü görülmektedir. Akademik başarısının etkilenmesi ile iletişime geçememe ve rahat hissedememe alt parametreleri değerlendirildiğinde istatistiksel açıdan anlamlı ilişki tespit edilememiştir $(\mathbf{p}=\mathbf{0 . 0 9 5}$, $\mathbf{p}=\mathbf{0 . 1 9 2}$ ) (Tablo 3). Gece cep telefonunu açık tutma, sabah kontrol etme ve günlük ortalama cep telefonu kullanım süresi ile akademik başarılarının etkilenmesi değerlendirildiğinde istatistiksel açıdan anlamlı ilişki tespit edilememiştir $\quad(\mathbf{p}=\mathbf{0 . 3 6 5}$, $\mathrm{p}=\mathbf{0 . 9 8 3}, \mathrm{p}=\mathbf{0 . 7 6 1}$ ).

\begin{tabular}{|c|c|c|c|c|}
\hline & & \multicolumn{2}{|c|}{ Akademik Başar1*** } & \multirow[t]{2}{*}{$\mathrm{p}$} \\
\hline & & Etkilenmiş & Etkilenmemiş & \\
\hline & & $28(\% 8.4)$ & $304(\% 91.6)$ & \\
\hline Bilgiye eriş & & $15.86 \pm 4.96$ & $15.20 \pm 5.29$ & $0.010^{*}$ \\
\hline Bağlantıyı & & $12.5[5-29]$ & $18[5-35]$ & $0.019 *$ \\
\hline İletişime gc & & $19.29 \pm 8.07$ & $23.76 \pm 9.04$ & 0.095 \\
\hline Rahat hiss & & $7.5[5-19]$ & $77.79[5-35]$ & 0.192 \\
\hline \multirow{3}{*}{$\begin{array}{l}\text { Nomofobi } \\
\text { skorları }\end{array}$} & Hafif & $20(\% 71.4)$ & $100(\% 32.9)$ & \multirow{3}{*}{$0.018^{* *}$} \\
\hline & Orta & $6(\% 21.4)$ & $168(\% 55.3)$ & \\
\hline & Aşırı & $2(\% 7.1)$ & $36(\% 11.8)$ & \\
\hline
\end{tabular}

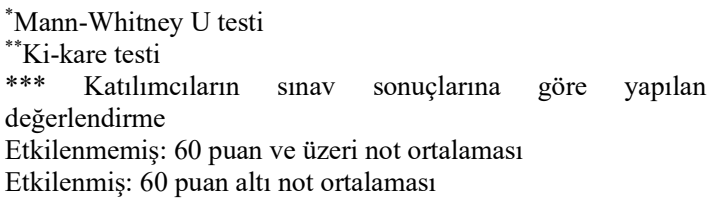

\section{TARTIŞMA}

İnsanlara oldukça cazip gelen cep telefonlarının yaygın kullanımı onları bazı sorunlarla baş başa bırakmıştır. Sağlıklı bireylerde endişeye yol açmazken, anksiyete bozukluğu olan bireylerde daha fazla sikıntı ve kaygıya sahip oldukları görülmektedir. ${ }^{5}$ Hayatımızın odak noktası haline gelen akıllı telefonların zararlı etkileri gün geçtikçe ortaya çıkmaktadır. ${ }^{14}$ Daha bilmediğimiz etkileri bulunan bu cihazlara biraz daha temkinli yaklaşmalıyız. Cep telefonları, bilgisayarlar ve diğer iletişim cihazları sürekli olarak kişilerarası etkileşimi ve sosyal alışkanlıkları etkilediği için sürekli olarak bireyleri izlemek zorundayı. ${ }^{15}$

Birçok ülkede üniversite öğrencileri arasındaki nomofobi prevalansı araştırılmıştır. Amerika Birleşik Devletleri Kentucky kentinde eczacılık fakültesi öğrencilerinde yapılan bir çalışmada $\% 56.8$ orta düzeyde ve \%18.2 şiddetli düzeyde nomofobi 
prevalansı bulunmuştur. ${ }^{16}$ Hindistan'da bir üniversitede yapılan bir çalışmada ise şiddetli nomofobi prevalansı $\% 23.5$ olarak bulunmuştur. ${ }^{17}$ Hindistan'da tıp öğrencilerinde yapılan bir çalışmada $\% 60$ oranında orta düzeyde ve $\% 22.1$ oranında ise şiddetli düzeyde nomofobi olduğu gösterilmiştir. ${ }^{18}$ Bizim yaptığımız çalışmada ise $\% 52.4$ orta düzeyde ve \%11.4 şiddetli düzeyde nomofobi olduğu tespit edilmiştir. Bizim çalışmamız, diğer ülkelerde yapılan çalışmalarla benzer niteliktedir. Orta ve şiddetli nomofobi oranları farklılı gösterse de genele baktığımızda \%60'ları geçen bir nomofobi prevalansı olduğu görülmektedir.

Günlük ortalama cep telefonu kullanım saatlerinin değerlendirildiği bir çalışmada üç saat ve üzeri kullanım oranı $\% 71$ olarak bulunmuştur. ${ }^{17}$ Bizim yaptığımız çalışmada da benzer şekilde \%72.9 olarak tespit edilmiştir. $\mathrm{Bu}$ oran sadece bize mesajlaştığı veya konuştuğu süre olarak cep telefonu kullanım saatini belirtmektedir. Kullanmadığ zamanlarda da cep telefonunun sürekli yanında olması ve çevrimiçi olması hali, kişileri dış uyaranlara her zaman açık hale getirmektedir. Bu durum kişinin o anki işine odaklanmasını etkilemektedir. Cep telefonu kullanım süresi arttıkça cep telefonu ile ilgili sorunların artmasina sebep olduğu bildirilmektedir. ${ }^{19}$ Farklı bir çalışmada akademik başarısını etkilediğini düşünenlerin oranı \%38.1 olarak değerlendirilmiştir. ${ }^{17}$ İran'da yapılan bir çalışmada ise cep telefonları ile harcadıkları zaman arttıkça derslerinden daha düşük notlar alacağını düşünen öğrencilerin oranı \%39.5 olarak bulunmuştur. ${ }^{19}$ Bizim çalışmamızda ise bu oran \%57.8 olarak bulunmuştur. Bu oranın bizde bu kadar yüksek olmasını tıp fakültesi öğrencileri olmalarına bağlayabiliriz. Eğitimlerinin zor olduğunun ve uzun çalışma saatlerinin olması gerektiğini bilen bu öğrenciler zamanlarının çoğunu alan bu cep telefonlarının onların akademik performansını düşürdüğünün farkındadır.

Sabah kalktığında cep telefonunu kontrol edenlere bakıldığında bizim çalışmamızda \%76 oranında hemen kontrol ettiğini belirtmiştir. Yapılan farklı bir çalışmada ise bu oran \% 55 olarak bulunmuştur. ${ }^{17}$ Ayrıca cep telefonunu kontrol sayısı arttıkça nomofobi düzeylerinin arttığ 1 gösterilmiştir ve öğrencilerin bunun olumsuz etkileri konusunda duyarlı hale getirilmesi gerekmektedir. ${ }^{20}$

Bizim yaptı̆̆ımız çalışmada cinsiyetler arası farklılıklar ile NMP-Q ölçeği değerlendirilmiş ve kadınlarda NMP-Q skorları daha yüksek bulunmuştur. Çalışmamız ile benzer sonuçlar bulan ya da arada fark bulamayan çalışmalar da bulunmaktadır. ${ }^{16,21}$ Hindistan 'da yapılan bir çalışmada ise erkeklerde bu oran daha yüksek bulunmuş ve bu o ülkede yaşayan erkeklerin özgürlüğüne bağlanmıştır. ${ }^{17}$ Bizim ülkemizde kadınların bazı çevrelerde sosyal ortamları sınırlı olsa da dijital ortamda sınırlarının olmaması ve rahat iletişim kurmalarından dolayı, nomofobi skorlarının daha yüksek olduğunu düşünmekteyiz.

NMP-Q ölçeği alt parametreleri değerlendirildiğinde bağlantıyı kaybetme ve bilgiye erişememenin daha fazla etkilendiği ve bunun akademik başarıya etkisinin daha fazla olduğu yaptığımız bu çalışmada gösterilmiştir. Özellikle genç nüfusta bu iki alt parametrenin etkilendiği diğer yapılan çalışmalarda da tespit edilmiştir. ${ }^{22}$

Çalışmamız tek bir merkezde yapılan bir çalışmadır ve tüm ülke için genelleyemeyiz. Aynı zamanda çalışmamız sadece tıp fakültesi öğrencilerini kapsadığı için diğer fakülte öğrencileri ile bir karşılaştırma yapılmamıştır. $\mathrm{Bu}$ durumlar çalışmamızın kısıtlılıklarını oluşturmaktadır.

Bizim yaptığımız bu çalışma daha önce yapılan çalışmalar üzerinde kurulmuş ve genişletilmeye çalışılmıştır. Tıp öğrencilerinde yapılan çalışmalar literatürde yer alsa da, onların akademik başarıları üzerine yapılmış olması haliyle bu çalışma bir ilktir.

Bu çalışmada öğrencilerin hem aldığı notları hem de bu konudaki düşüncelerini birlikte değerlendirdik. Her iki değerlendirmede de etkilenmelerin olduğunu tespit ettik. Ancak katılımcıların \%57.8'i akademik başarılarının etkilediğini düşündüğünü belirtmesine rağmen, aldıkları not ortalamasına göre yapılan değerlendirmede etkilenme oranısadece \%8 olarak tespit edildi. $\mathrm{Bu}$ iki oran arasında büyük bir fark vard. $\mathrm{Bu}$ farkın ana sebebi ise başarı not ortalamasının resmi olarak 60 puan olmasina rağmen, öğrencilere göre 60 puandan daha yüksek puanların başarılı olarak kabul edilmesinden kaynaklandığını düşünmekteyiz. Hatta öğrencilerin aldıkları puanlara göre yapılan değerlendirmede, etkilenen grupta ağır NMP-Q skorları olan öğrenci sayısının (n:2), etkilenmeyen gruptaki ağır NMP-Q skoru olan öğrenci sayısına (n:36) göre daha az olması, sınavlarda alınan puanların resmi olarak başarılı görülmesine rağmen, öğrenciler için bir başarı olarak görülmediğini düşündürmektedir. Diğer bir ifade ile öğrenciler sınavlarda 60 puan ve üzerinde bir not almış, ancak aldıkları puanı kendileri için yeterli olarak görmediklerini düşündürmektedir.

Yapılan çalışmalar cep telefonu kullanımının akademik başarıyı olumsuz yönde etkilediğini net bir şekilde ortaya koymuştur. $\mathrm{Bu}$ durum, cep telefonu kullanımının dikkat dağınıklığına sebep olması ve kesintisiz çalışılan ders zamanının azalmasına bağlanmıştır. ${ }^{23,24}$ Hemşireler üzerinde yapılan farklı bir çalışmada nomofobinin onların akademik başarısını düşürdüğü ve aynı zamanda dikkat dağınıklığı yaparak klinik performanslarını dadüşürdüğü gösterilmiştir. ${ }^{25}$ Yapılan bu çalışmalar bu konuda mutlaka önlem alınması gerektiğini göstermektedir. Hemşirelerde olduğu gibi 
hekimlerde de bu konu çok önemlidir. Tıp eğitimi hem uzun hem de zor bir eğitim süreci içermektedir. Öğrencilerin gereken önemi verememesi ya da zamanını ayıramaması ve bunun sonucunda da eğitimlerinin etkilenmesi, eğitim kalitesinin düşmesine sebep olmaktadır. Bunun sonucunda ortaya çıkabilecek bir hata geri dönüşü olmayan sonuçlara sebep olabilir.

Biz bu çalışmada katılımcıların sınav ortalamalarına göre akademik başarılarını değerlendirdiğimizde NMP-Q skorları arttıkça akademik başarılarının düştüğünü tespit ettik. Öte yandan sınav ortalamalarından bağımsız olarak kişisel görüşlerine göre de akademik başarılarını etkilediğini tespit ettik. NMP-Q skorları her iki açıdan da bakıldığında akademik başarıyı düşürdüğünü göstermiş olduk. $\mathrm{Bu}$ bize kimi öğrenciye göre alması gerektiği notun altında alması ya da yeterince ders çalışmaya zaman ayıramamasını bir başarısızlık olarak değerlendirdiğini ve akademik başarısını etkilediğini düşündüğünü göstermektedir. Akademik başarıda sadece sınav sonuçları değil bireysel görüşlerinin de önemli olduğunu düşünmekteyiz.

Sonuç olarak, eğitim kalitesinin artırılmasında teknolojik cihazlar işimizi kolaylaştırabilir. Fakat öğrencilere sınırlı kullanımın olması gerektiği anlatılmalıdır. $\mathrm{Bu}$ durum zamanında önlem alınmazsa, ilerleyen zamanda bir halk sağlığı sorunu olarak karşımıza çıkabilir.

\section{Teşekkür}

Çalışmamızın istatistiksel analizi için yardımlarını esirgemeyen Bolu Abant İzzet Baysal Üniversitesi Tıp Fakültesi Bilimsel Çalışmalar Destekleme Birimi’ne teşekkür ederiz.

\section{Çıkar çatışması}

Bu bilimsel çalışmada herhangi bir çıkar çatışması bulunmamaktadır.

\section{Maddi Kaynak}

$\mathrm{Bu}$ bilimsel çalışmada herhangi bir maddi destek sağlayan kurum ya da kişi bulunmamaktadır.

\section{KAYNAKLAR}

1. İletişim Hizmetleri İstatistikleri. https://www.btk.gov.tr/iletisim-hizmetleriistatistikleri.[Erişim Tarihi: 18.02.2020].

2. Mobile Fact Sheet. https://www.pewresearch.org/internet/factsheet/mobile/. [Erişim Tarihi: 18.02.2020]. 3. Hanehalkı Bilişim Teknolojileri Kullanım Araştırması

2016.http://tuik.gov.tr/PreHaberBultenleri.do?id=21 779. [Erişim Tarihi: 18.02.2020].

4. Kwon M, Kim DJ, Cho H, Yang S. The smartphone addiction scale: development and validation of a short version for adolescents. PLoS One. 2013;8(12):e83558.

5. King ALS, Valença AM, Silva AC, Sancassiani F, Machado S, Nardi AE. "Nomophobia": impact of cell phone use interfering with symptoms and emotions of individuals with panic disorder compared with a control group. Clin Pract Epidemiol Ment Health. 2014;10:28.

6. Daei A, Ashrafi-Rizi H, Soleymani MR. Nomophobia and health hazards: smartphone use and addiction among university students.Int J Prev Med. 2019;10:202.

7. Tavolacci M-P, Meyrignac G, Richard L, Dechelotte P, Ladner J. Problematic use of mobile phone and nomophobia among French college students.Eur J Public Health. 2015;25(suppl_3):206 8. Bragazzi NL, Del Puente G. A proposal for including nomophobia in the new DSM-V. Psychol Res Behav Manag. 2014;7:155-60.

9. Lee SY. Examining the factors that influence early adopters' smartphone adoption: the case of college students. Telematics and Informatics. 2014;31(2):308-18.

10. Chou H-L, Chou C. A quantitative analysis of factors related to Taiwan teenagers' smartphone addiction tendency using a random sample of parentchild dyads. Comput Human Behav. 2019;99:33544 .

11. Pavithra M, Madhukumar S, Mahadeva M. A study on nomophobia-mobile phone dependence, among students of a medical college in Bangalore. . Ntl J of Community Med. 2015;6(3):340-4.

12. Yildirim C, Correia A-P. Exploring the dimensions of nomophobia: development and validation of a self-reported questionnaire. Comput Human Behav. 2015;49:130-7.

13. Yildirim C, Sumuer E, Adnan M, Yildirim S. A growing fear: prevalence of nomophobia among Turkish college students. Information Development. 2016;32(5):1322-31.

14. Nikhita CS, Jadhav PR, Ajinkya SA. Prevalence of mobile phone dependence in secondary school adolescents. J Clin Diagn Res. 2015;9(11):6-9 
15. De-Sola Gutiérrez J, Rodríguez de Fonseca F, Rubio G. Cell-phone addiction: A review. Fron Psychiatry. 2016;7:175.

16. Cain J, Malcom DR. An assessment of pharmacy students' psychological attachment to smartphones at two colleges of pharmacy.Am J Pharm Educ. 2019;83(7):7136.

17. Jilisha G, Venkatachalam J, Menon V, Olickal JJ. Nomophobia: a mixed-methods study on prevalence, associated factors, and perception among college students in Puducherry, India. Indian J Psychol Med. 2019;41(6):541-8.

18. Farooqui IA, Pore P, Gothankar J. Nomophobia: an emerging issue in medical institutions? J Ment Health. 2018;27(5):438-41.

19. Darvishi M, Noori M, Nazer MR, Sheikholeslami S, Karimi E. Investigating different dimensions of nomophobia among medical students: a cross-sectional study.Open Access Maced J Med Sci. 2019;7(4):573-8.

20. Abraham N, Mathias J, Williams S. A study to assess the knowledge and effect of nomophobia among students of selected degree colleges in Mysore. Asian Journal of Nursing Education and Research. 2014;4(4):421-8.

21. Basu S, Garg S, Singh MM, Kohli C. Addiction-like behavior associated with mobile phone usage among medical students in Delhi. Indian J Psychol Med. 2018;40(5):446-51.

22. Adnan M, Gezgin D. Modern yüzyılın yeni olgusu nomofobi ve üniversite öğrencileri arasında yaygınlık düzeyi. Ankara Üniversitesi Eğitim Bilimleri Fakültesi Dergisi. 2016;49(1):141-58.

23. Lepp A, Barkley JE, Karpinski AC. The relationship between cell phone use and academic performance in a sample of US college students. Sage Open. 2015;5(1):1-9

24. Lepp A, Barkley JE, Karpinski AC. The relationship between cell phone use, academic performance, anxiety, and satisfaction with life in college students. Comput Human Behav. 2014;31:343-50.

25. Gutierrez-Puertas L, Marquez-Hernandez VV, Sao-Romao-Preto L, Granados-Gamez G, Gutierrez-Puertas V, Aguilera-Manrique G. Comparative study of nomophobia among Spanish and Portuguese nursing students. Nurse Educ Pract. 2019;34:79-84. 